\title{
Electret Stability Related to the Crystallinity in Polypropylene
}

\author{
Thyssen, Anders; Almdal, Kristoffer; Thomsen, Erik Vilain
}

Published in:

Proceedings of IEEE Sensors 2015

Link to article, DOI:

10.1109/ICSENS.2015.7370665

Publication date:

2015

Document Version

Peer reviewed version

Link back to DTU Orbit

Citation (APA):

Thyssen, A., Almdal, K., \& Thomsen, E. V. (2015). Electret Stability Related to the Crystallinity in Polypropylene. In Proceedings of IEEE Sensors 2015 (pp. 1879-1882). IEEE. https://doi.org/10.1109/ICSENS.2015.7370665

\section{General rights}

Copyright and moral rights for the publications made accessible in the public portal are retained by the authors and/or other copyright owners and it is a condition of accessing publications that users recognise and abide by the legal requirements associated with these rights.

- Users may download and print one copy of any publication from the public portal for the purpose of private study or research.

- You may not further distribute the material or use it for any profit-making activity or commercial gain

- You may freely distribute the URL identifying the publication in the public portal

If you believe that this document breaches copyright please contact us providing details, and we will remove access to the work immediately and investigate your claim. 


\title{
Electret Stability Related to the Crystallinity in Polypropylene
}

\author{
Anders Thyssen, Kristoffer Almdal and Erik V. Thomsen \\ Technical University of Denmark \\ Department of Micro and Nanotechnology \\ Ørsteds Plads 345Ø, 2800 Kgs. Lyngby, Denmark
}

\begin{abstract}
Through mixing isotactic-polypropylene (i-PP) and atactic-polypropylene (a-PP), we have demonstrated the importance of the crystallinity in polypropylene as an electret material. Samples with crystallinities between $7 \%$ and $47 \%$ were used. A high degree of crystallinity in polypropylene, used as an electret, gives a better charge stability with respect to temperature and humidity changes. The semicrystalline i-PP significantly outperforms a-PP regarding charge stability. a-PP is an amorphous polymer. By mixing a-PP and i-PP, the degree of crystallinity can be controlled, while all other sample preparation processes and characteristics can be identical. This is important since the performance of an electret material is sensitive to its previous process history. Activation energies used for predicting the thermal potential decay are determined from thermally stimulated current and isothermal potential decay experiments. Activation energies from $0.98 \mathrm{eV}$ to $1.41 \mathrm{eV}$ were determined. From these values, a very good agreement was achieved between the experimental potential decay at room temperature for more than $\mathbf{2 9 0}$ days, and a theoretical estimation of the potential decay.

Index Terms - electrets, crystallinity, charge stability, humidity stability, spherulites, thermally stimulated currents, isotactic-polypropylene, atactic-polypropylene.
\end{abstract}

\section{INTRODUCTION}

Electret materials are dielectrics with quasi-permanent electric charges or dipole polarization and they are often used where it is favorable to utilize a permanent electrical field for example in electret microphones, [1]-[3], where the use of an electret material makes it possible to make a microphone without an embedded power supply. Typically, highly stable electret materials, such as perfluoro polymer electrets, are used [4], [5].

In this work, however, polypropylene, in its isotactic and atactic form, is used as a model system for investigating the discharge mechanisms in polymer electret materials. The goal is to get an understanding of how to enhance the temperature and humidity stability for polypropylene and to be able to transfer this knowledge to other electret polymers. Polypropylene is chosen as a model system due to the limited charge lifetime compared to other much more stable electrets but the results obtained are equally

Manuscript received on October 2016, in final form June 2017. important for an optimization of the electret properties of polypropylene. Elevated temperature and controlled humidity conditions are used as accelerated aging conditions. This makes it possible to study the performance of polypropylene as an electret material much faster than other more stable electret polymers. Polypropylene is structurally similar to the popular perfluoro polymer electrets such as perfluoronated ethylene propylene copolymer (FEP) and polytetrafluoroethylene. Both the fluoropolymers and polypropylene are semicrystalline and in the case of FEP also have sidechains with one carbon atom -either methyl or trifluoromethyl. However, the fluoropolymers are both with respect to processing and physical characterization much more difficult to handle than polypropylene.

In reference [6], [7] it has been revealed that the electrical charges in polymer electrets are associated with the crystalline spherulites, in particular the center of these. In [8] we have demonstrated that the size of the spherulites are of major importance to the charge stability. The influence of the degree of crystallinity is, however, to be determined. Others have succeeded in increasing the charge stability in 
polymer electrets by other means than control of the size of the crystalline areas or the degree of crystallinity, for example through treatment with titanium-tetrachloride vapor [9], the introduction of particles [10] or other impurities [11], or by biaxially stretching the electret material [12]. All this in the search of making even better electret materials which for example can be used in smallscale vibrational energy harvesters, air filters or prepolarized microphones; e.g. electret microphones [4], [13].

\section{THEORY}

This section covers the theory regarding thermally stimulated discharging of electrets and the location of the charges.

When having an electret material with real charges (surface or space charges), the charges can be thought of as being trapped in potential wells; as known from solid state physics [14], [15]. The activation energy or energies if multiple traps exist, for loss of charge is a measure of how deep these potential wells are and how stable the charges are on/in the electret. The higher the activation energy is, the more stable the charges are. By thermally stimulating the charges, the depth of the traps can be revealed.

\subsection{KINETIC RATE THEORY}

When heating up a charged electret, its discharge mechanisms are accelerated. This discharging, can be seen as a current that leaves the electret and can be described by general second order reaction kinetics, which are given by [16]-[18]. Several other authors have also used reaction kinetics to describe the electret discharge phenomenon [19], [20].

$$
\begin{aligned}
& I(t)=q \frac{d n}{d t}=\frac{q n^{2}}{A_{n} / A_{h}(N-n)+n} v \exp \left(\frac{E_{a}}{k_{b} T}\right) \\
& I(T)=q \frac{d n}{d T}=\frac{q n^{2}}{A_{n} / A_{h}(N-n)+n} \frac{v}{\beta} \exp \left(\frac{E_{a}}{k_{b} T}\right)
\end{aligned}
$$

where $I$ is the current as a function of time, $t$, or temperature, T. $q$ is the elementary charge, $n$ is the number of electrons on the electret at any given time or at any given temperature and $N$ is the total number of available traps. $A_{n}$ and $A_{h}$ are the probability coefficients for an electron being re-trapped and for an electron to recombine with a hole in a recombination center, respectively. $\beta$ is the linear heating rate and $E_{a}$ is the activation energy of the trap. $v$ is the rate constant with the dimension inverse time and can be interpreted as an attempt-to-escape frequency. This parameter is proportional to the frequency of the collisions between the electron and the material phonons. Finally, $k_{b}$ is the Boltzmann's constant.

Equation (1) describes the discharge behavior for isothermal conditions, whereas equation (2) describes the discharge behavior when the temperature is linearly increased. From a combination of isothermal potential decay experiments and thermally stimulated current measurements the activation energy of the trap, or traps, can be determined. For $A_{n} / A_{h}=\{0,1\}$ the solution to equation (1) is given by

$$
n(t)=\frac{\frac{A_{n}}{A_{h}} N}{\left(1-\frac{A_{n}}{A_{h}}\right) W\left(\frac{A_{n}}{A_{h}} \exp \left(\frac{v t \exp \left(\frac{E_{a}}{k_{b} T}\right)-\frac{A_{n}}{A_{h}}}{\frac{A_{n}}{A_{h}}-1}\right) / \frac{A_{n}}{A_{h}}-1\right)}
$$

where $W$ is the Lambert $\mathrm{W}$ function [21]. The solution to equation (2) is similar.

For $A_{n} / A_{h} \neq\{0,1\}$ a numerical approach is needed to solve equation (1) and equation (2).

Note that this theory only applies for materials where the phase state is preserved, and cannot be used to describe the discharge mechanism when e.g. a polymer begins to melt. This is primarily because the theory does not account for molecular motion in the electret. If an electret has traps with different energies, the discharge behavior can be explained by a superposition of either equation (1) or equation (2), depending whether it is the time of temperature domain that is in use. The different terms, of the superposition, should be mutually weighted with the initial amount of charges, $n_{0}$.

\subsection{UNCERTAINTY ON THE ACTIVATION ENERGY}

The activation energy, $E_{a}$, and the attempt-to-escape frequency, $v$, are strongly correlated, which often make it necessary to fix $v$ to a specific value, normally in the interval $10^{12} \mathrm{~s}^{-1}$ to $10^{14} \mathrm{~s}^{-1}$ [18]. However, when fixing $v$, an uncertainty to the activation energy is also introduced. This uncertainty comes from the possibility of a wrong estimate of $v$. For the case where $A_{n} / A_{h}=1$ it can be shown that the error introduced on the activation energy, of course, depend on the correct values of the attempt-to-escape frequency, $v_{\mathrm{c}}$, but also on the temperature, $T_{p}$, of which the largest current for equation (2) occurs [22]. This is seen as a current peak when plotting equation (2) as a function of temperature. The error for the activation energy is given by the relation

$$
\text { Error on } E_{a} \cong k_{b} T_{p} \ln \left(\frac{v}{v_{c}}\right)
$$

By a numerical approach it can be shown that the error given by equation (4) depends only weakly on the ratio of $A_{n} / A_{h}$, the heating rate, $\beta$, the number of available traps, $N$, relative to the number of electrons at the start temperature, $T_{0}$, and the initial guess of $v$.

By using equation (4), it can be shown that the error when estimating an activation energy range from $0.07 \mathrm{eV}$ for a current peak at $80{ }^{\circ} \mathrm{C}$ to $0.08 \mathrm{eV}$ for a current peak located at $130{ }^{\circ} \mathrm{C}$. This estimate is valid assuming that the guess of $v$ is within an order of magnitude from the true value. Thus, it will not be possible to determine the activation energy with more than two significant digits, under the assumption above. A current peak at $80{ }^{\circ} \mathrm{C}$ and 
$130{ }^{\circ} \mathrm{C}$ corresponds to an activation energy of $1.047 \mathrm{eV}$ and $1.122 \mathrm{eV}$ respectively; using $v=10^{13}, A_{n} / A_{h}=1, \quad N=n_{0}$, $\beta=7.5 \mathrm{~K} / \mathrm{min}$.

\section{SAMPLE PREPARATION AND EXPERIMENTAL PROCEDURE}

This section covers the details regarding sample preparation and experimental procedures.

\subsection{SUPPORT STRUCTURE AND SPIN COATING}

All samples consist of a support structure and a spin coated layer of either isotactic polypropylene (i-PP), atacticpolypropylene (a-PP) or a mixture hereof. The i-PP has a weight average molecular weight of $250,000 \mathrm{~g} / \mathrm{mol}$, a number average molecular weight of $67,000 \mathrm{~g} / \mathrm{mol}$ and was purchased as beads. The weight average molecular weight for the a-PP was $12,000 \mathrm{~g} / \mathrm{mol}$ and the a-PP was in the form of a waxy gel. The supplier of the i-PP was Sigma-Aldrich and the supplier of the a-PP was Goodfellow.

The support structures consist of a single side polished, $10 \mathrm{~cm}$ diameter, highly doped silicon wafer with a $100 \mathrm{~nm}$ thick layer of titanium on the front side. The titanium provides good electrical conductivity throughout the support structure and ensures the adhesion of polypropylene to the front side. A highly doped silicon wafer was chosen as support structure due to its very low electrical resistivity, which is below $0.025 \mathrm{ohm} \cdot \mathrm{cm}$, and flatness.

The polypropylene was spin coated onto the support structure, from a polypropylene/cyclohexane solution. Four mixtures were used where the content of the polypropylene was changed as follows (by weight): 1) $100 \% \mathrm{i}-\mathrm{PP}$, 2) $2 / 3$ i-PP and $1 / 3$ a-PP, $\quad$ 3) $1 / 3$ i-PP and $2 / 3$ a-PP, and 4) $100 \%$ a-PP. Prior to spin coating, mixture 1), 2) and 3) had been heated to $120{ }^{\circ} \mathrm{C}$ in a closed vial for at least 18 hours to ensure complete dissolution of the polypropylene beads. Before use, the solution is cooled to $78{ }^{\circ} \mathrm{C}$. At this temperature the solution is metastable with respect to crystallization induced precipitation of the i-PP. The time window of use, at $78{ }^{\circ} \mathrm{C}$, is approximately 1 hour. The $120^{\circ} \mathrm{C}$ heat treatment can be repeated and the solution reused. Mixture 4) forms a homogenous suspension at room temperature and, thus, did not need to be heated.

The spin coating process was tuned to the four different mixtures so that the final thickness became around $30 \mu \mathrm{m}$ to $40 \mu \mathrm{m}$. After each spin coating, the samples were heat treated in an oven at $180{ }^{\circ} \mathrm{C}$ for $2 \mathrm{~min}$., this is to ensure complete evaporation of the cyclohexane and to reduce the internal stress in polypropylene, which was introduced during spin coating.

\subsection{PRESS AND COOLING}

To ensure a consistent surface morphology the samples were pressed at $10 \mathrm{bar}$ and $180^{\circ} \mathrm{C}$ for $5 \mathrm{~min}$ in a mechanical press. The sample to be pressed is covered by a silver-coated silicon wafer. The silver is a non-adherent surface. Around the sample and the silver-coated wafer, silicone rubber sheets are used to ensure an even distribution of the pressure. The thickness of the polypropylene after this treatment is approximately $30 \mu \mathrm{m}$.

After the samples have been pressed, they are exposed to quenching in an ice bath, going from $180{ }^{\circ} \mathrm{C}$ to $0{ }^{\circ} \mathrm{C}$ in approximately $1 \mathrm{~s}$. This is to ensure small size spherulites, which work done previously [8] concluded was very important to obtain a good charge stability.

As all the used samples, has been quenched in the same way we assume that all samples had the same spherulite size. The difference in crystallinity, therefore, originates from the number rather than the size of the spherulites.

\subsection{CRYSTALLINITY}

The crystallinity of the samples was determined with a Differential Scanning Calorimeter (DSC) 4000 from Perkin Elmer. $8 \mathrm{mg}$ to $15 \mathrm{mg}$ of polypropylene was removed from the substrates for each analysis. The crystallinity stated in this work is an average of a minimum of six runs. The heating rate was $20^{\circ} \mathrm{C} / \mathrm{min}$ and the crystallinity was calculated from the ratio of the melting peak, from the first cycles, to the heat of fusion for polypropylene $(165 \mathrm{~J} / \mathrm{g}$ [23]).

\subsection{CHARGING AND SURFACE POTENTIAL}

The samples were charged in a corona discharge setup for $2 \mathrm{~min}$. The principle behind the setup is described in [24]. The distance from the needle to the grid was $3 \mathrm{~cm}$ and the distance from the grid to the sample was $3 \mathrm{~mm}$. The grid was used as a common ground for the needle and the sample, and the potential from the needle to the grid was fixed at $-10 \mathrm{kV}$ using an EMCO high voltage component "Q101N". The potential from the grid to the sample can be controlled from $0 \mathrm{~V}$ to $2000 \mathrm{~V}$ using an EMCO USB high voltage power supply "USB20P". All samples were charged to $-500 \mathrm{~V}$ and left at ambient conditions for a minimum of 12 hours before being used in any experiments. This was done because we are interested in the long-term stability of the electrets and we would like to exclude the short time decay from the experiments.

The reason that the electret are charged negative is due to the fact that several authors have reported that negative charge electrets are slightly more stable than positive charged ones [19], [20]. The -500 V correspond to a charge density similar to what is used in commercial products, such as electret microphones. We note that the charge density is below level at which cross-over is expected - the phenomenon where a surface decay curve starting at one voltage crosses and curved starting at another voltage [24].

The surface potential has been measured with an electrostatic voltmeter located $1 \mathrm{~mm}$ to $2 \mathrm{~mm}$ above the surface of the samples. The electrostatic voltmeter used was a Trek 347 with probe $6000 \mathrm{~B}-7 \mathrm{C}$.

Samples used in the following potential decay experiments were not recharged for new decay experiments. Some of the samples were, however, used after the decay 
experiments to determine the degree of crystallinity, which was a destructive process.

\subsection{ISOTHERMAL POTENTIAL DECAY}

The isothermal potential decay experiments were conducted at $90{ }^{\circ} \mathrm{C}$ and at $120{ }^{\circ} \mathrm{C}$, both for 24 hours. Each sample was measured five times in the 24-hour period. Each measurement is performed by a robot that took 101 independent readings of the surface potential evenly distributed over the wafer, with a minimum distance to the edge of $10 \mathrm{~mm}$. At each measurement, all samples were taken out of the oven and returned when all the measurements had been performed. The relative humidity for the isothermal experiment was below $2 \% \mathrm{RH}$.

\subsection{HUMIDITY INDUCED POTENTIAL DECAY}

The humidity induced potential decay experiment was conducted at $50{ }^{\circ} \mathrm{C}$ and $90 \% \mathrm{RH}$ for 24 hours. The climate chamber used was a Vötsch VC 4060. Each sample was measured in the same way as the samples at the isothermal experiments. The samples used for the humidity experiment were not reused for other experiments.

\subsection{TERMALLY STIMULATED CURRENT}

The thermally stimulated current has been calculated from a thermally stimulated potential decay experiment, which is where the surface potential, is measured as a function of a linear increased temperature. The temperature was controlled with a programmable hotplate, EchoTherm Model HS60 from Torrey Pines Scientific. The used heating rate was $7.5 \mathrm{~K} / \mathrm{min}$. The released current from the electret was calculated from the measured surface potential with the following expression:

$$
I(T)=\frac{\varepsilon_{0} \varepsilon_{r}}{d} \beta \frac{d V}{d T}
$$

where $\varepsilon_{0}$ is the is the vacuum permittivity, $\varepsilon_{r}$ the relative permittivity, $\beta$ the heating rate, $V$ the measured surface potential, $T$ the temperature and $d$ the thickness of the sample. It is here assumed that all the charges are located at the surface of the electret [25].

Note that correction has not been included for the nonlinear thermal expansion of the polypropylene [26], since this is not important in the context of electret stability related to polypropylene crystallinity.

\subsection{BEST-FIT APPROACH}

In section 4.3, the term "best-fit approach" is used. This term covers how equation (1) and (2) has been mathematically fitted to experimental data points. MATLAB [27] has been used for this purpose with the build in function lsqcurvefit which is a solver for nonlinear curve-fitting problems in a least-squares sense.

\section{RESULTS}

This section covers the results from the experiments described in section 3. Unless stated otherwise, each data

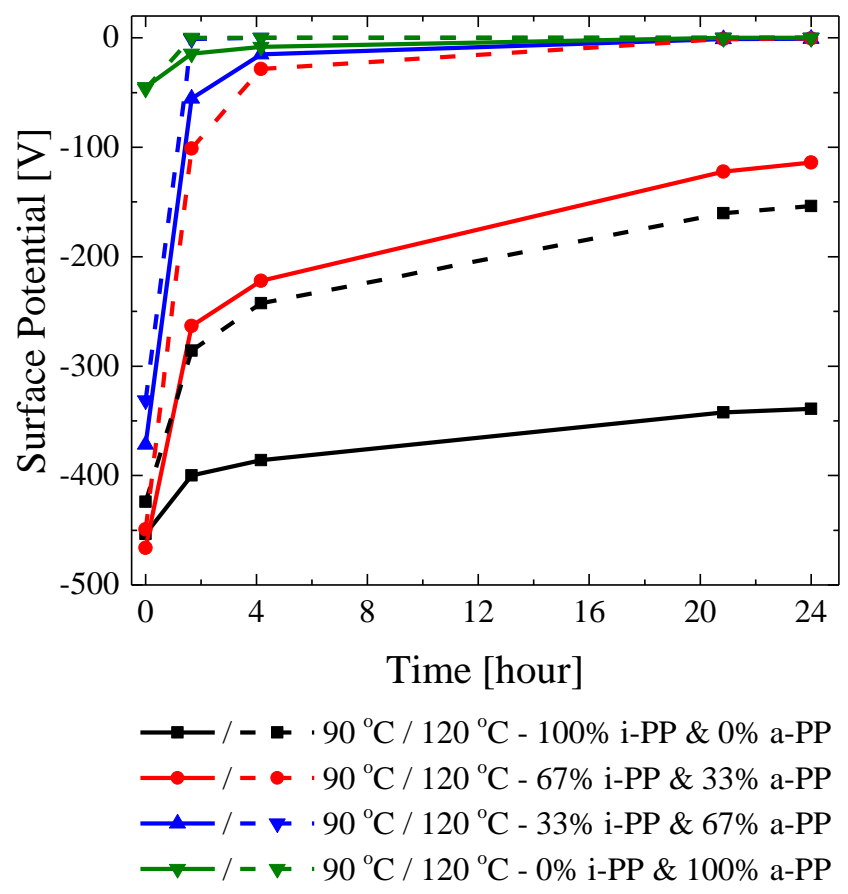

Figure 1. The isothermal charge stability at $90{ }^{\circ} \mathrm{C}$ and $120{ }^{\circ} \mathrm{C}$. As the content of the a-PP is increased, the charge stability is significantly reduced. The fully amorphous samples, the samples that only contained a-PP, are so unstable that they loose more than $450 \mathrm{~V}$ from the end of charging to the start of the isothermal experiments.

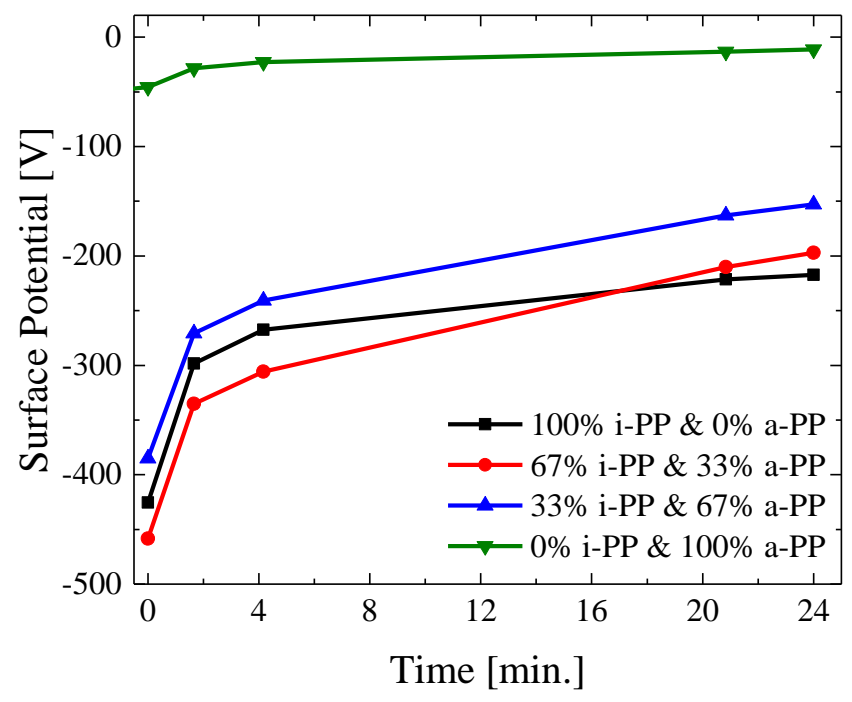

Figure 2. The charge stability at $50{ }^{\circ} \mathrm{C}$ and $90 \%$ relative humidity. It is seen that after 24 hours the samples with the least amount of a-PP are the most stable.

point is based on an average from four equivalent samples, each with 101 different measuring points.

\subsection{THERMAL AND HUMID CHARGE STABILITY}

Figure 1 shows the isothermal charge stability at $90^{\circ} \mathrm{C}$ and $120^{\circ} \mathrm{C}$. As the content of the a-PP is increased, the charge stability is substantially reduced. The samples that only contain a-PP were so unstable that they lost more than $250 \mathrm{~V}$ from the end of charging to the start of the first surface potential measurement, a transfer that takes approximately 2 min. As seen in Figure 1 this sample type 


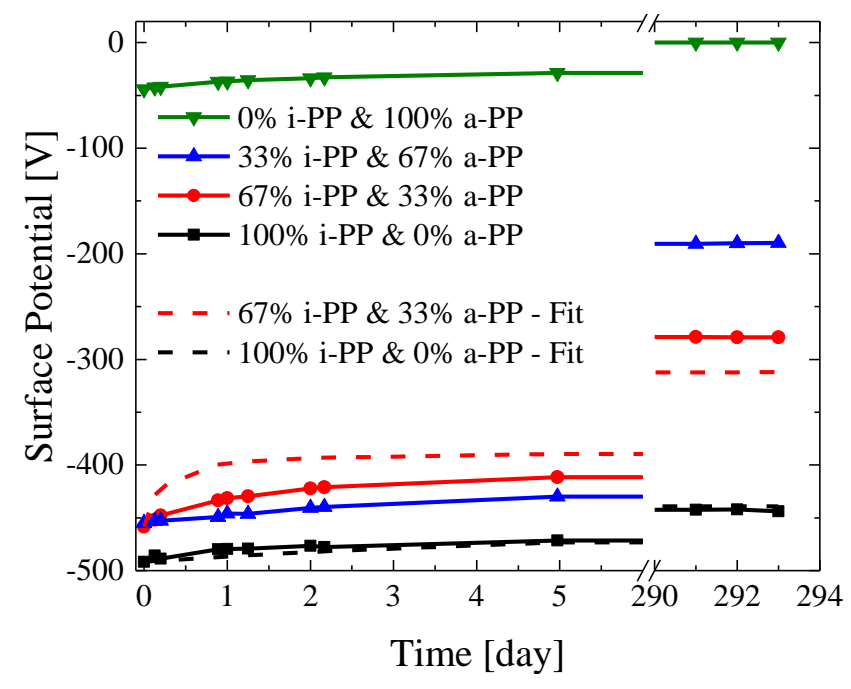

Figure 4. The charge stability for four reference samples. The four samples had been stored at room temeprature. Comparring this figure with Figure 1 and Figure 2, it is easy to see the thermal effect on the charge stability. The fits are described in the end of section 4.3.

lost on average $450 \mathrm{~V}$ in the 12 hours period from the samples being charge to the experiments started.

In Figure 2, the charge stability at $50{ }^{\circ} \mathrm{C}$ and $90 \%$ relative humidity is seen. Again, it is seen that after 24 hours the samples with the least amount of a-PP are the most stable and that the samples with $100 \%$ a-PP drop most of their charges before the actual experiment began.

Figure 4 shows the charge stability for four samples over a period of 293 days. The samples were stored in a cleanroom single wafer carrier box and kept away from direct sunlight. The temperature has been the indoor temperature of the session; $18-25^{\circ} \mathrm{C}$.

In Figure 3 the charge stability after 24 hours is replotted as a function of degree of crystallinity.

The changes seen at ambient conditions (Figure 4) are augmented under stressful conditions. Thus the difference, seen in Figure 4, over long time, between the three crystalline samples, are reflected in the faster and more dramatic changes seen in Figure 1 and Figure 2. The sample containing $1 / 3$ i-PP and $2 / 3$ a-PP in Figure 4 (blue curve, $\mathbf{\Delta}$ ) were somewhat at odds the first 5 days with the interpretation from Figure 1 and Figure 2. This sample is characterized by a 10 fold larger variation in the surface potential, than the other samples, which may account for the fact that this sample, in the first 5 days, appears more stable in Figure 4 than the more crystalline sample consisting of $2 / 3$ i-PP and $1 / 3$ a-PP (red curve, $\bullet$ ). However after 291 day (and most likely before) the charge stability trend at ambient conditions is similar to what is reflected under the more stressful conditions, namely that the samples containing the most i-PP have the best charge stability. This correlates well with the crystallinity of the samples.

\subsection{CRYSTALLINITY}

The crystallinity of the different types of samples has been calculated from DSC analysis and the results are listed
Table 1 The percent's in both columns are by weight.

\section{Sample Crystallinity}

\begin{tabular}{r|c}
\hline \multicolumn{1}{c|}{ Samples } & Crystallinity \\
\hline $100 \%$ i-PP & $47 \%$ \\
\hline $67 \%$ i-PP \& $33 \%$ a-PP & $39 \%$ \\
\hline $33 \%$ i-PP \& $67 \%$ a-PP & $22 \%$ \\
\hline $100 \%$ a-PP & $7 \%$ \\
\hline
\end{tabular}

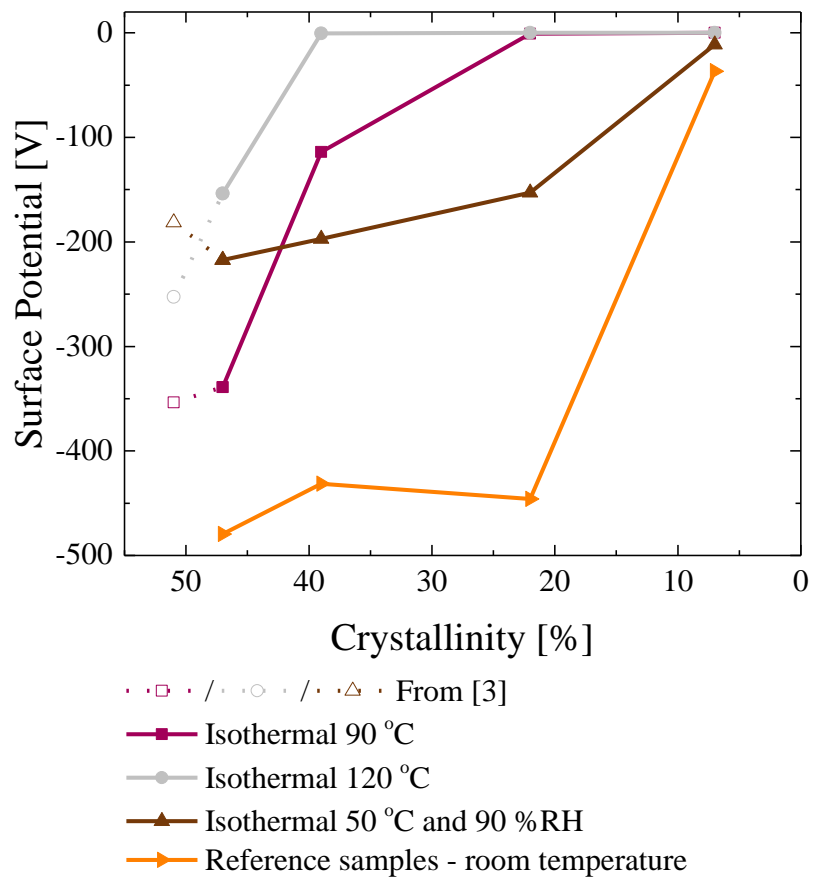

Figure 3. Charge stability after 24 hours as a function of crystallinity for the different aging methods. Data from [8] are included.

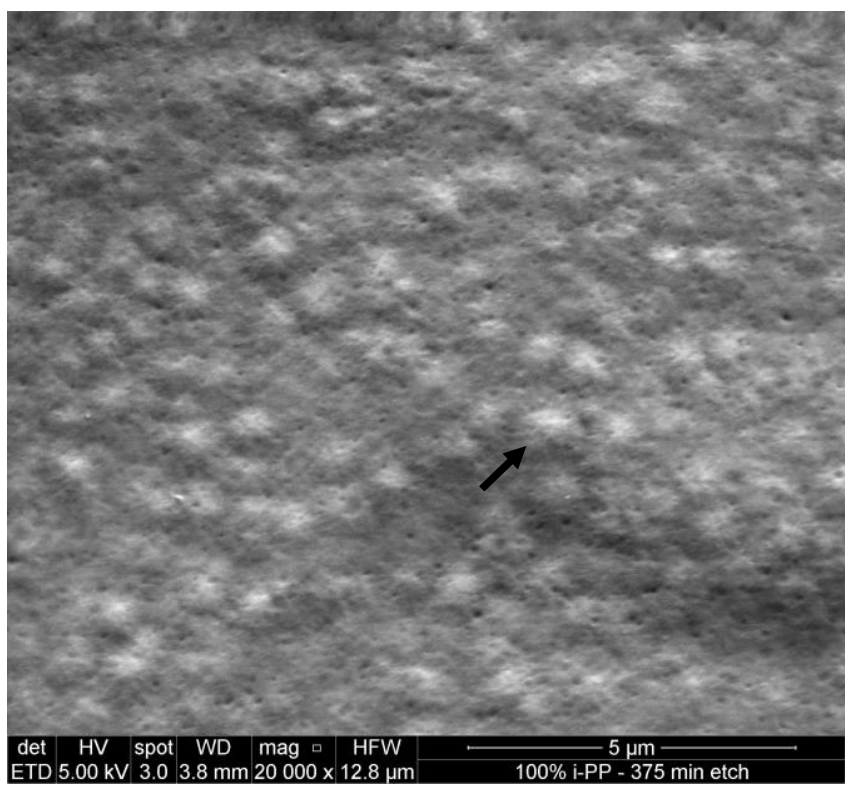

Figure 5. SEM image of a sample that consist of $100 \%$ i-PP. What appears as bumps (one is indicated by the black arrow) are sherulites at the surface of the sample, which all are smaller than $1 \mu \mathrm{m}$. 
in Table 1. What is seen is that the crystallinity decreases as the amount of i-PP is lowered. This is expected, as a-PP is an amorphous polymer. We note that the calculated crystallinity is $7 \%$ for the samples only consisting of a-PP, indicates that the used a-PP is not $100 \%$ atactic as specified by the manufacturer.

Figure 3 shows the surface potential after 24 hours as a function of the crystallinity for the different sample types. The solid lines represent data from Figure 1 to Figure 4 and the dashed lines represent data from previous work [8]. In Figure 3, a clear correlation is seen between increased charge stability and an increased degree of crystallinity. The higher the degree of crystallinity the better the charge stability will be. However, since the size of the crystalline areas, known as spherulites, plays an even bigger role than the crystallinity [8], increasing the crystallinity should not happen through increased spherulites size but through an increased number spherulites.

The size of the spherulites in these set of experiments have been smaller than $1 \mu \mathrm{m}$, which have been confirmed by Scanning Electron Microscopy (SEM) on samples that prior to the SEM have been exposed to a selective etch as described in [28], [29]. A SEM image from a sample consisting of $100 \%$ i-PP is seen in Figure 5. The areas that appear as bumps are the spherulites. The black arrow in the middle of the image indicates one of these spherulites.

\subsection{RELEASE CURRENT}

Figure 7 shows the calculated thermally stimulated current for a sample consisting of $2 / 3 \mathrm{i}-\mathrm{PP} \& 1 / 3 \mathrm{a}-\mathrm{PP}$, at the heating rate of $7.5 \mathrm{~K} / \mathrm{min}$, along with four states, that can describe the released current up to $150{ }^{\circ} \mathrm{C}$. The four states are based on equation (2) that describes general second order reaction kinetic. The current seen in Figure 7 above $150{ }^{\circ} \mathrm{C}$ cannot be described by the theory discussed in section 2 as polypropylene melts in the interval $150{ }^{\circ} \mathrm{C}$ to

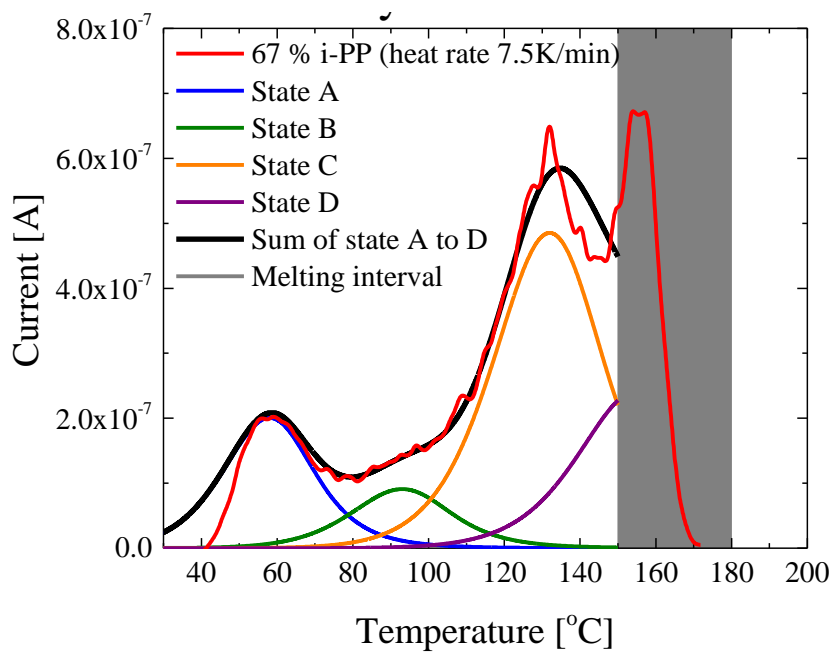

Figure 7. Calculated released current for the sample type consisting of $2 / 3$ i-PP \& $1 / 3$ a-PP at a heating rate of $7.5 \mathrm{~K} / \mathrm{min}$, along with four states that accounts for the released current up to the melting of the sample. The four activation energies along with other relevant parameters for the states can be seen in Table 2 . $180^{\circ} \mathrm{C}$. This melting interval has been determined by differential scanning calorimeter. For the four states in Figure $7 v$ has been fixed to $v=10^{13}$ and the ratio of $A_{n} / A_{h}$ has been set to 0.5 as this value gives the best fit to the flank (the right side of a current peak) for the three current peaks with the lowest temperature. $N$, the number of available traps, has been set equal to $n_{0}$ (the initial amount of charges), as it is assumed that the deepest traps are filled first.

The activation energies for state $\mathrm{A}, \mathrm{B}$ and $\mathrm{C}$ have initially been determined from the temperature position of the current peaks by the following numerical approach. After determining the activation energies for state $\mathrm{A}$ and state $\mathrm{C}$, which were $0.98 \mathrm{eV}$ and $1.21 \mathrm{eV}$ respectively, the activation energy for state B could be determined from the peak that occurred when subtracting state $\mathrm{A}$ and state $\mathrm{C}$ from the experimental data (the red curve in Figure 7). The activation energy for state B was determined to $1.09 \mathrm{eV}$. The sum of states $\mathrm{A}, \mathrm{B}$ and $\mathrm{C}$ account for almost $61 \%$ of the released current in Figure 7 and it is therefore fair to assume, the

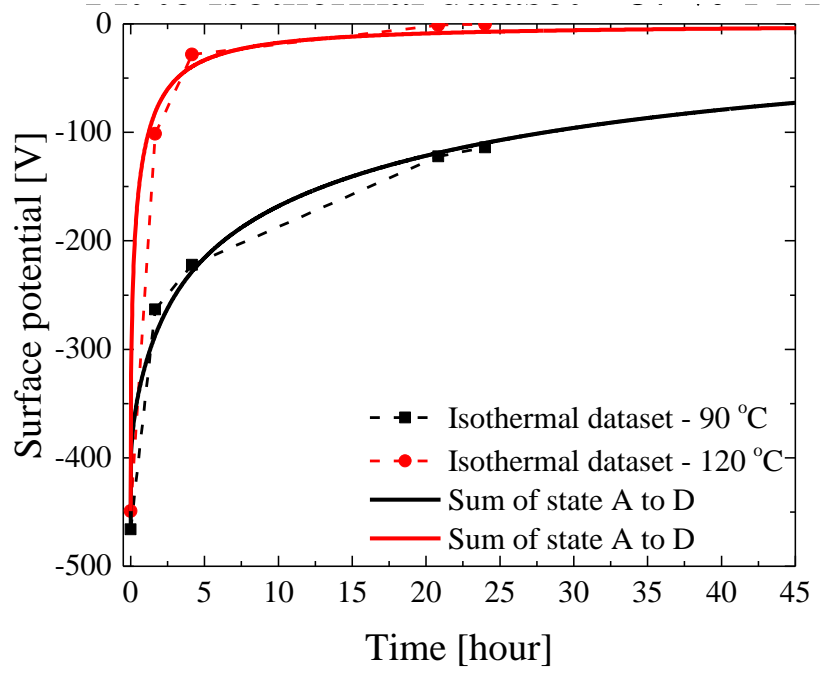

Figure 6. Results for the sample type consisting of $2 / 3$ i-PP \& $1 / 3$ a-PP. The theoretical isothermal potential decay (solid curves), together with the experimental data (dots) presented in Figure 1 are shown. The theoretical potential decay is based on three activation energies determined from Figure 7 and a fourth activation energy determined from a best-fit approach to the $90{ }^{\circ} \mathrm{C}$ isothermal experimental data (black dots). As seen the theoretically predicted potential decay fits very well with the experimental data. The fourth activation energy and the $\mathrm{R}^{2}$ values for the fits are given in Table 2.

Table 2 Activation energies, and other relevant parameters for the four states visible in Figure 7 and Figure 6 . †Thermally stimulated Current. \$Thermally stimulated Potential Decay.

\begin{tabular}{c|c|c|c|c}
\hline $\begin{array}{c}\text { 67 \% } \\
\text { i-PP }\end{array}$ & $\begin{array}{c}\text { Based } \\
\text { on }\end{array}$ & Weighting & $\boldsymbol{E}_{\#[e V]}$ & $\begin{array}{c}\text { Peak } \\
\text { Temperature }\end{array}$ \\
\hline Fit A & $\mathrm{TSC}^{\dagger}$ & $15.1 \%$ & 0.98 & $58^{\circ} \mathrm{C}$ \\
\hline Fit B & $\mathrm{TSC}$ & $7.5 \%$ & 1.09 & $93{ }^{\circ} \mathrm{C}$ \\
\hline Fit C & $\mathrm{TSC}$ & $38.3 \%$ & 1.21 & $132^{\circ} \mathrm{C}$ \\
\hline Fit D & $\mathrm{TSPD}$ & $39.1 \%$ & 1.28 & $155^{\circ} \mathrm{C}$ \\
\hline$v=10^{13}$ & $N=\mathrm{n}_{0}$ & $A_{\mathrm{n}} / A_{\mathrm{h}}=0.5$ & $\mathrm{R}_{90^{\circ} \mathrm{C}}^{2}=0.992$ & $\mathrm{R}_{120^{\circ} \mathrm{C}}^{2}=0.996$ \\
\hline
\end{tabular}


existence of minimum one more trap with an activation energy above $1.26 \mathrm{eV}$; which correspond to a current peak above $150{ }^{\circ} \mathrm{C}$. All the above-mentioned values are summarized in Table 2.

The last type of trap, state $\mathrm{D}$, has been determined by combining the data from the calculated release current and the data from the $90{ }^{\circ} \mathrm{C}$ isothermal experiment (from Figure 1) by a best-fit approach, described in section 3.8. This was done using the three activation energies from state A, B and $\mathrm{C}$, as initial guess and then assuming the existence of one more trap that should account for the rest of the charges with an activation energy above $1.26 \mathrm{eV}$. The initial guess on their mutual weighting was based on results from the initial determination of state $\mathrm{A}, \mathrm{B}$ and $\mathrm{C}$. With this approach, the activation energy for state $\mathrm{D}$ has been determined to $1.28 \mathrm{eV}$. The uncertainty on the activation energy from the fitting routine is $\pm 0.004 \mathrm{eV}$, which is much smaller than the uncertainty given by the fixed value of $v$; this was discussed in section 2.2. The solid black and red curve in Figure 6 is the theoretical potential decay at $90{ }^{\circ} \mathrm{C}$ and $120{ }^{\circ} \mathrm{C}$ respectively for the sample type consisting of $2 / 3 \mathrm{i}-\mathrm{PP} \& 1 / 3 \mathrm{a}-\mathrm{PP}$ using the four above determined activation energies and their weighting. As seen the theoretically predicted decay fits very well with what has been observed experimentally the first 24 hours, and when extrapolating the fits beyond the first 24 hours the predicted decay seems reasonable. The coefficient of determination $\left(R^{2}\right)$ for the two predicted decays in Figure 6 are 0.992 and 0.996 for the $90{ }^{\circ} \mathrm{C}$ fit and the $120{ }^{\circ} \mathrm{C}$ fit respectively. These values are also summarized in Table 2.

The determination of the activation energies for the sample consisting of $100 \% \mathrm{i}-\mathrm{PP}$ is done with the same approach as for the sample consisting of $2 / 3 \mathrm{i}-\mathrm{PP} \& 1 / 3 \mathrm{a}-\mathrm{PP}$. However, as seen in Figure 8, only a single current peak is visible, for the released current with a heating rate of $7.5 \mathrm{~K} / \mathrm{min}$ before the sample begins to melt. As the current

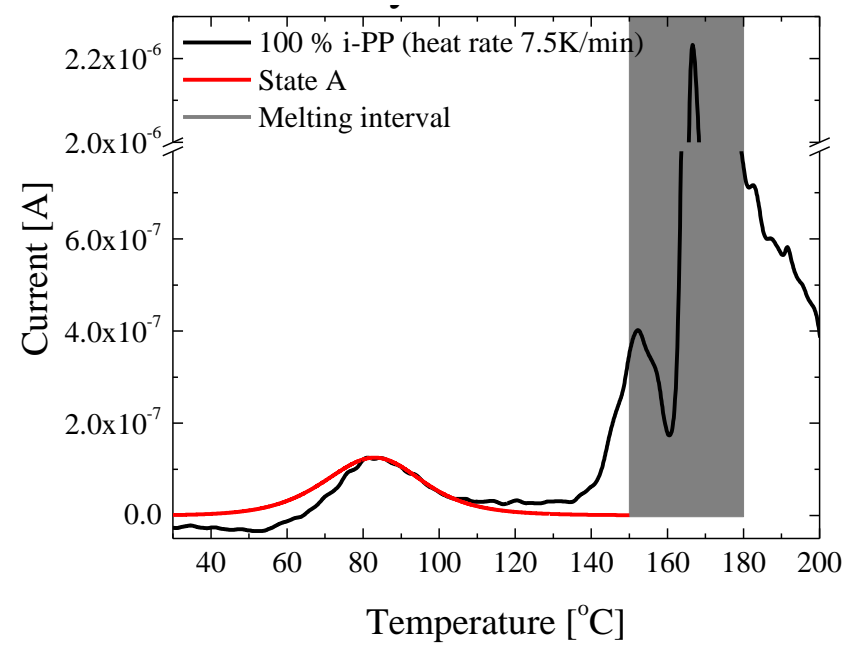

Figure 8. Shows the calculated released current for the sample type consisting of $100 \% \mathrm{i}-\mathrm{PP}$ at a heating rate of $7.5 \mathrm{~K} / \mathrm{min}$. Only one current peak is seen before the sample begins to melt, meaning that only one activation energy can be determined from the thermally stimulated current. The activation energy along with other relevant parameters for the state can be seen in Table 3 . peak is located at $83{ }^{\circ} \mathrm{C}$ the activation energy can be determined to $1.06 \mathrm{eV}$. The weighting of state A in Figure 8 has been determined to $10.7 \%$ of the total released current. The above-mentioned values are also summarized in Table 3 . From the released current in Figure 8 it is fair to assume the existence of at least one more trap with an activation energy above $1.26 \mathrm{eV}$, which, as previously mentioned, corresponds to a current peak above $150{ }^{\circ} \mathrm{C}$. By using the same approach as for the sample consisting of $2 / 3$ i-PP \& $1 / 3$ a-PP, a good fit is obtained for the data from the $90{ }^{\circ} \mathrm{C}$ isothermal experiment. However, a significant underestimation of the charge retention is made for the data from the $120^{\circ} \mathrm{C}$ isothermal experiment. This indicates the existence of yet another type of trap, which will result in a larger charge retention for the fit at $120^{\circ} \mathrm{C}$.

Figure 9 shows the results of a best-fit approach using the data from both the $90{ }^{\circ} \mathrm{C}$ and the $120^{\circ} \mathrm{C}$ isothermal experiments from Figure 1. The activation energy and its weighting determined from the released current in Figure 8 has been used together with the assumption of two additional traps that should account for the rest of the charges. This resulted in two activation energies of $1.29 \mathrm{eV}$ and $1.41 \mathrm{eV}$ with weightings of the total charge of $40.3 \%$

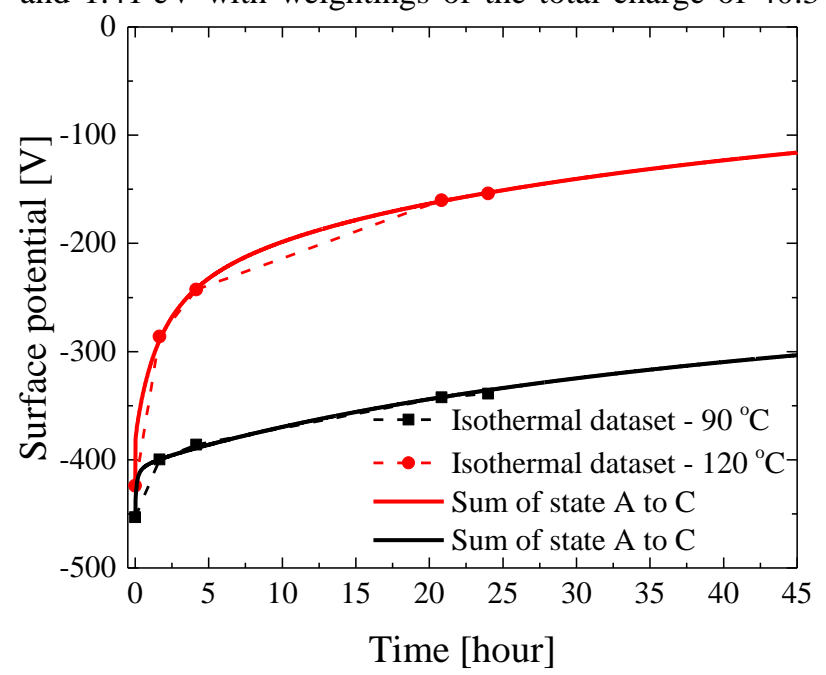

Figure 9. The theoretical potential decay based on the activation energy determined from Figure 8 and two additional activation energies determined from a best-fit approach to both the $90{ }^{\circ} \mathrm{C}$ and $120^{\circ} \mathrm{C}$ isothermal experimental data (red and black dots). As seen the theoretically predicted potential decay fits very well with the experimental data. All three activation energies and the $\mathrm{R}^{2}$ values for the fits are shown in Table 3.

Table 3 Activation energies, and other relevant parameters for the three states found in Figure 8 and Figure 9. $\dagger$ Thermally stimulated Current.

¥Thermally stimulated Potential Decay.

\begin{tabular}{c|c|c|c|c}
\hline $\begin{array}{c}\mathbf{1 0 0} \% \\
\boldsymbol{i}-\boldsymbol{P P}\end{array}$ & $\begin{array}{c}\text { Based } \\
\text { on }\end{array}$ & Weighting & $\boldsymbol{E}_{\#}[\mathrm{eV}]$ & $\begin{array}{c}\text { Peak } \\
\text { Temperature }\end{array}$ \\
\hline State A & TSC $\dagger$ & $10.7 \%$ & 1.06 & $83^{\circ} \mathrm{C}$ \\
\hline State B & TSPD $\$$ & $40.3 \%$ & 1.30 & $161{ }^{\circ} \mathrm{C}$ \\
\hline State C & TSPD & $49.0 \%$ & 1.41 & $199^{\circ} \mathrm{C}$ \\
\hline$v=10^{13}$ & $N=n o$ & $A_{n} / A_{h}=0.5$ & $R_{90^{\circ} \mathrm{C}}^{2}=0.998$ & $R_{120^{\circ} \mathrm{C}}^{2}=1.000$ \\
\hline
\end{tabular}


and $49.0 \%$ respectively. The theoretical current peaks for both activation energies lies well in or above the melting interval of i-PP; at $161{ }^{\circ} \mathrm{C}$ and $199{ }^{\circ} \mathrm{C}$ respectively. As seen in Figure 9, the theoretical predicted decay fits very well with the experimental data from the $90{ }^{\circ} \mathrm{C}$ and the $120^{\circ} \mathrm{C}$ isothermal experiments. Moreover, when extrapolating the fits beyond the first 24 hours the predicted decay seems reasonable. The correlation coefficients, $\mathrm{R}^{2}$-values from the fits, for the two predicted decays in Figure 9 are 0.998 and 1.000 for the $90{ }^{\circ} \mathrm{C}$ fit and the $120{ }^{\circ} \mathrm{C}$ fit respectively. The above-mentioned values are also given in Table 3 .

We note that the discussion presented assumes that we are characterizing potential decay for samples which are unchanged when temperature is changed and, thus, we are examining processes which occur with increased rate at higher temperature. This model of course breaks down at the melting point where any residual charge is lost and shown up as strong peak in the thermally stimulated decay. We are hesitant to discuss the nature of this final decay in detail since it is fundamentally different from the other decay mechanisms.

By using the four activation energies given in Table 2 and the three activation energies listed in Table 3 the theoretical potential decay for the two reference samples in Figure 4 , consisting of $2 / 3$ i-PP \& $1 / 3$ a-PP and $100 \%$ i-PP respectively can be determined. These two fits are shown by the dashed lines in Figure 4, and it is seen that the predicted potential decay, for a period of 293 days, for the sample consisting of $2 / 3$ i-PP \& $1 / 3$ a-PP are fairly good and very good for the sample that only consist of $100 \% \mathrm{i}-\mathrm{PP}$.

\section{CONCLUSION}

On the basis of the presented work, we conclude that the best charge stability is achieved with a high degree of crystallinity. We have demonstrated this with respect to temperature and humidity.

The degree of crystallinity has been controlled by mixing a-PP in i-PP, while all other process parameters have been kept constant, as charge stability in electret materials is known to be sensitive to the process history.

The samples with highest crystallinity exhibited significantly better charge stability in comparison to the samples with lower crystallinity.

We emphasize the importance of the small size of the spherulites [8]. The size of the spherulites was determined using SEM to be smaller than $1 \mu \mathrm{m}$.

The determination of the activation energies for the samples consisting of $100 \%$ i-PP and $2 / 3$ i-PP \& $1 / 3$ a-PP has shown that the theory described in section 2 can be used for describing the thermal discharge mechanism for polymer electrets both for short but also for a longer period of time which was demonstrated for samples that had been stored for 293 days. This gives a powerful tool of estimating the lifetime of an electret at different thermal conditions.

\section{REFERENCES}

[1] G. Sessler and J. West, "Directional transducers," IEEE Trans. Audio Electroacoust., vol. 19, no. 1, pp. 19-23, Mar. 1971.

[2] G. M. Sessler and J. E. West, "Electret transducers: a review," $J$. Acoust. Soc. Am., vol. 53, no. 6, p. 1589, 1973.

[3] N. E. and H. M. E. Frederiksen, "Techincal Review No. 4 1979," May 1979

[4] R. Kressmann, G. M. Sessler, and P. Gunther, "Space-charge electrets," IEEE Trans. Dielectr. Electr. Insul., vol. 3, no. 5, pp. 607-623, Oct. 1996.

G. M. Sessler, "Electrets Vol. 1," 3rd ed., Laplacian Press, 1998, pp. 347-382.

K. Ikezaki, A. Yagishita, and H. Yamanouchi, "Charge trapping sites in spherulitic polypropylene," in Proceedings of 8th International Symposium on Electrets (ISE 8), 1994, pp. 428433.

A. Yagishita, K. Ikezaki, and H. Yamanouchi, "Charge trapping sites in spherulitic polypropylene," Japanese J. Appl. Physics, Part 1 Regul. Pap. Short Notes Rev. Pap., vol. 38, no. 4A, pp. 2053-2058, 1999.

A. Thyssen, K. Almdal, and E. V. Thomsen, "Electret Stability Related to Spherulites in Polypropylene," IEEE Trans. Dielectr. Electr. Insul., vol. 22, no. 5, pp. 2858-2863, 2015.

D. Rychkov, R. Gerhard, V. Ivanov, and A. Rychkov, "Enhanced electret charge stability on polyethylene films treated with titanium-tetrachloride vapor," IEEE Trans. Dielectr. Electr. Insul., vol. 19, no. 4, pp. 1305-1311, Aug. 2012.

] N. Mohmeyer et al., "Additives to improve the electret properties of isotactic polypropylene," Polymer (Guildf)., vol. 48, no. 6, pp. 1612-1619, Mar. 2007.

1] D. P. Erhard, D. Lovera, C. Von Salis-Soglio, R. Giesa, V. Altstädt, and H. W. Schmidt, "Recent advances in the improvement of polymer electret films," Adv. Polym. Sci., vol. 228, no. 1, pp. 155-207, 2010.

J. Hillenbrand, N. Behrendt, V. Altstädt, H.-W. Schmidt, and G. M. Sessler, "Electret properties of biaxially stretched polypropylene films containing various additives," J. Phys. D. Appl. Phys., vol. 39, no. 3, pp. 535-540, Feb. 2006.

[13] A. Crovetto, F. Wang, and O. Hansen, "An electret-based energy harvesting device with a wafer-level fabrication process," $J$. Micromechanics Microengineering, vol. 23, no. 11, p. 114010, 2013.

[14] D. A. Neamen, Semiconductor physics and devices: basic principles. McGraw-Hill, 2003.

[15] C. Kittel, Introduction to Solid State Physics, 8th Editio. John Wiley \& Sons, 2004.

[16] G. F. J. Garlick and A. F. Gibson, "The Electron Trap Mechanism of Luminescence in Sulphide and Silicate Phosphors," Proc. Phys. Soc., vol. 60, no. 6, pp. 574-590, Jun. 1948.

[17] C. . Sunta, W. E. . Ayta, J. F. . Chubaci, and S. Watanabe, "General order and mixed order fits of thermoluminescence glow curves -a comparison," Radiat. Meas., vol. 35, no. 1, pp. 47-57, Jan. 2002.

[18] V. Pagonis, G. Kitis, and C. Furetta, Numerical and practical exercises in thermoluminescence. Springer, 2006.

[19] J. van. Turnhout, Thermally stimulated discharge of polymer electrets. A study on nonisothermal dielectric relaxation phenomena. Elsevier, 1975.

[20] G. M. Sessler, Electrets Vol. 1, 3rd ed. Laplacian Press, 1998.

[21] R. M. Corless, G. H. Gonnet, D. E. G. Hare, D. J. Jeffrey, and D. E. Knuth, "On the LambertW function," Adv. Comput. Math., vol. 5, no. 1, pp. 329-359, Dec. 1996.

[22] A. Thyssen, "Charge Distribution and Stability in Electret 
Materials," Technical University of Denmark, 2016.

[23] B. Wunderlich, Macromolecular Physics 3. London: Academic Press, 1980.

[24] J. A. Giacometti and O. N. Oliveira, "Corona charging of polymers," IEEE Trans. Electr. Insul., vol. 27, no. 5, pp. 924 943, 1992.

[25] R. Ono, M. Nakazawa, and T. Oda, "Charge Storage in CoronaCharged Polypropylene Films Analyzed by LIPP and TSC Methods," IEEE Trans. Ind. Appl., vol. 40, no. 6, pp. 1482 1488, Nov. 2004.

[26] Y. Okada, "The thermal expansion coefficient of polypropylene and related composites," McGrill University, Montreal, Canada, 1992.

[27] "MATLAB R2015a," Version 2015a, 20-Jan-2015. [Online]. Available: www.mathworks.com. [Accessed: 20-Jan-2016].

[28] M. Aboulfaraj, B. Ulrich, A. Dahoun, and C. G'Sell, "Spherulitic morphology of isotactic polypropylene investigated by scanning electron microscopy," Polymer (Guildf)., vol. 34, no. 23, pp. 4817-4825, Jan. 1993.

[29] J. Park, K. Eom, O. Kwon, and S. Woo, "Chemical Etching Technique for the Investigation of Melt-crystallized Isotactic Polypropylene Spherulite and Lamellar Morphology by Scanning Electron Microscopy," Microsc. Microanal., vol. 7, no. 3, pp. 276-286, Feb. 2002.

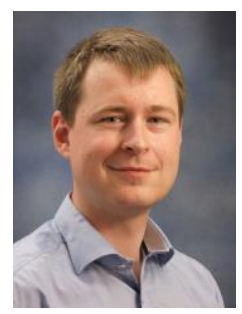

A. Thyssen was born in Toftlund, Denmark in 1986. He received his M.Sc and Ph.D. from the Technical University of Denmark, Kgs. Lyngby, Denmark in 2012 and 2016. He is currently working in the industry.

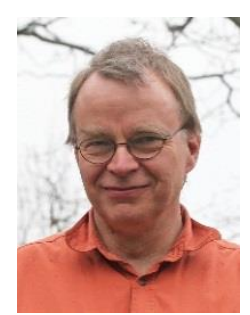

K. Almdal (born in Frederiksberg, Denmark 1958). $\mathrm{He}$ received his M.Sc. and Ph.D. from the University of Copenhagen in 1985 and 1989. His research interests include polymer synthesis, polymer physics, polymer degradation and selforganization phenomena in particular in block copolymers. He is currently professor in polymers in micro- and nanotechnology at the Technical University of Denmark in Kgs. Lyngby. He is elected member of the Danish Academy of Natural Sciences and Danish Academy of Technical Science.

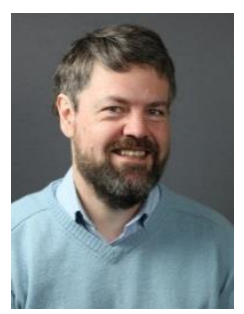

E. V. Thomsen was born in Aarhus, Denmark, in 1964. He received the M.Sc. degree in physics from Odense University, Odense, Denmark, and the $\mathrm{Ph} . \mathrm{D}$. degree in electrical engineering from the Technical University of Denmark (DTU),Kgs. Lyngby, in 1998. He has been affiliated with the Department for Micro and Nanotechnology, DTU, since $1992 . \mathrm{He}$ is group leader for the MEMS Applied Sensors Group. His current research and teaching interests include Electret based devices,

MEMS multisensors; bio-medical devices; small scale energy systems, such as miniature fuel cells and energy harvesting devices; capacitive micromachined ultrasonic transducers; and piezoelectric MEMS. He teaches classes in solid-state electronics, microtechnology, and nano- and microfabrication. Dr. Thomsen received the AEG Electron Prize in 1995 and has received several teaching awards at DTU. 